Article

\title{
Crystal Orientation Dependence of the Portevin-Le Chatelier Effect in Instrumented Indentation: A Case Study in Twinning-Induced Plasticity Steels
}

\author{
Xiuxing Peng ${ }^{1,2, *}$, Lingyu Wang ${ }^{1}\left(\mathbb{D}\right.$, Wei $X u^{1}$ and Zhiyuan Liang ${ }^{2}(\mathbb{D}$ \\ 1 State Key Laboratory of Rolling and Automation, Northeastern University, Shenyang 110819, China; \\ wanglingyu@ral.neu.edu.cn (L.W.); xuwei@ral.neu.edu.cn (W.X.) \\ 2 Songshan Lake Materials Laboratory, Dongguan 523808, China; liangzhiyuan@sslab.org.cn \\ * Correspondence: pengxiuxing@stumail.neu.edu.cn
}

Citation: Peng, X.; Wang, L.; Xu, W.; Liang, Z. Crystal Orientation Dependence of the Portevin-Le Chatelier Effect in Instrumented Indentation: A Case Study in Twinning-Induced Plasticity Steels. Metals 2022, 12, 439. https://doi.org/ $10.3390 /$ met12030439

Academic Editor: Eric Hug

Received: 31 December 2021 Accepted: 14 February 2022 Published: 2 March 2022

Publisher's Note: MDPI stays neutral with regard to jurisdictional claims in published maps and institutional affiliations.

Copyright: (C) 2022 by the authors. Licensee MDPI, Basel, Switzerland. This article is an open access article distributed under the terms and conditions of the Creative Commons Attribution (CC BY) license (https:// creativecommons.org/licenses/by/ $4.0 /)$.

\begin{abstract}
Instrumented indentation can be effectively used to investigate the Portevin-Le Chatelier (PLC) effect at small scales. It has been shown that the PLC effect in single crystals may depend on the crystal orientation, yet the underlying mechanism is unclear. Here, the orientation dependence of the PLC effect was systematically studied by conducting instrumented indentation tests in the [001]-, [101]- and [111]-oriented grains of a polycrystalline twinning-induced plasticity steel. It is found that the crystal orientation does not affect the PLC effect at relatively high indentation strain rates. In contrast, there is a strong orientation dependence at lower rates, with enhanced difficulty in the formation of serrations in the order of the [001], [111] and [101] orientations. This finding contradicts the previous proposals of the orientation effects, which are associated with the dislocation waiting time. On the basis of both the orientation and rate effects observed here, we proposed that the crystal orientation influences the occurrence of serrations in instrumented indentation by affecting the number of activated slip systems and, therefore, the probability of finding sufficient dislocation sources to accommodate the plastic avalanche.
\end{abstract}

Keywords: Portevin-Le Chatelier effect; instrumented indentation; crystal orientation; serration; negative strain rate sensitivity

\section{Introduction}

The Portevin-Le Chatelier (PLC) effect is a phenomenon of plastic instability that manifested as serrations on the stress-strain curves and the formation of PLC bands [1,2]. It is generally accepted that the PLC effect results from negative strain rate sensitivity (nSRS), which is caused by dynamic strain aging (DSA) [3,4]. When dislocations encounter local obstacles and stop temporarily, solute atoms can diffuse to the dislocation cores and pin the dislocations. The dislocations cannot move unless the applied stress is sufficiently high for them to break from obstacles. DSA is the process of dislocations moving and being pinned by solute atoms when they are temporarily arrested [5,6]. DSA occurs when the dislocation waiting time is longer than the solute diffusion time [4,7].

The PLC effect depends on several factors such as the temperature [8], strain rate [9,10] and solute concentration [11]. The effects of crystal orientation on the PLC effect have been investigated in $\mathrm{Al}$ alloys. For instance, Cheng et al. [12] showed that the stress drop of serrations at the traverse direction of a cold-drawn $\mathrm{Al}-\mathrm{Mg}$ alloy was more than $70 \%$ higher than that at the rolling direction. A similar phenomenon has also been observed in the Al-Li and Al-Cu alloys [13-15]. Additionally, it was also found that the PLC effect appeared more frequently when the textured samples were loaded uniaxially at certain directions, which was interpreted as the orientation effects on the dislocation velocity $[16,17]$. However, it is noted that the materials in the aforementioned investigations contain precipitates that are arranged along certain crystal plane. It has been reported that the PLC effect can be 
caused by the interaction between precipitates and dislocations $[18,19]$. In this condition, it is difficult to determine the real influence of orientation on the PLC effect.

In addition, the effects of crystal orientation have also been investigated through tensile or compression tests along various orientations of bulk single crystals. Kalk et al. [20] conducted compression tests in single crystals at the orientations for either single slip or multiple slip. The critical stress for the occurrence of serrations in the single-slip single crystals is four times more than that of the multi-slip samples. This phenomenon was explained by the effects of slip systems on the dislocation waiting time. Specifically, the waiting time at a certain applied strain rate is longer in the multi-slip samples, which facilitates the occurrence of serrations. While uniaxial tests in bulk single crystals serve as an effective approach to study the orientation effects, the preparation of single crystals and meanwhile the control of crystal orientations are challenging for many alloys. Alternatively, instrumented indentation tests conducted within the grains of selected orientations, offer an efficient and more universal way to examine the orientation effects. An attempt in this regard was made by Kovàcs et al. [21] by conducting micro-indentation tests in an $\mathrm{Al}-\mathrm{Zn}$ $\mathrm{Mg}-\mathrm{Cu}$ alloy. They found that plastic instabilities, i.e., the indentation serrations, are more pronounced when the diagonal of the Vickers indenter coincided with the $<110>$ crystal direction in the $<100>$-oriented grain. They proposed that the instabilities are enhanced in this configuration of orientation because it allows multiple slips during indentation. Henry et al. [22] investigated the anisotropy of the PLC effect in an AZ91 Mg alloy by instrumented indentation tests with a spherical indenter. Orientations with high activity of pyramidal II $<\mathrm{c}+\mathrm{a}>$ slip increase the forest dislocation density. The PLC effect is more significant in such orientations because of the enhancement of the interaction between solute and forest dislocation.

While the aforementioned studies have provided some important observations of the influence of crystal orientation on the PLC effect, the underlying mechanisms are still not clear. To address this issue, instrumented indentation experiments were systematically carried out within the [001]-, [101]- and [111]-oriented grains in a twinning-induced plasticity (TWIP) steel with a notable PLC effect. The indentation strain rate was varied from $5 \times 10^{-4}$ to $10^{-1} \mathrm{~s}^{-1}$. The current results indicate that the influence of orientation on the PLC effect becomes noticeable only at the lower indentation strain rates, i.e., in a condition when the waiting time is sufficiently long for the solute segregation. This finding contradicts the previous proposals of the orientation effects that are associated with the dislocation waiting time. On the basis of both the orientation and rate effects observed here, an alternative explanation for the influence of crystal orientation on the PLC effect was provided.

\section{Materials and Methods}

A TWIP steel with a chemical composition of Fe-12Mn-1.2C (wt.\%) was used to investigate the orientation dependence of the PLC effect. This TWIP steel was selected because it exhibits a notable PLC effect at room temperature $[9,23]$. The sample with the dimensions of $12 \times 4 \times 2.4 \mathrm{~mm}^{3}$ was cut from the cold-rolled sheet with $60 \%$ thickness reduction by electrical discharge machining. In order to obtain a fully recrystallized coarsegrained structure, the sample was annealed at $1373 \mathrm{~K}$ for an hour in a vacuum furnace filled with argon gas. Both surfaces of the annealed sample was ground off by a certain thickness $(\sim 0.3 \mathrm{~mm})$ to eliminate the effect of potential decarbonization layers. Then, the sample was polished with sandpapers and diamond suspensions. The last step was the mechanical-chemical polishing with a colloidal silica suspension (particle size: $40 \mathrm{~nm}$ ) for $30 \mathrm{~min}$ to obtain a damage-free surface. The crystal orientation of the sample was characterized using electron backscatter diffraction (EBSD) in a ZEISS Gemini 300 field emission scanning electron microscope (SEM). EBSD maps were collected with a 2- $\mu \mathrm{m}$ scanning step size at an acceleration voltage of $30 \mathrm{keV}$. As demonstrated by a typical inverse pole figure in Figure 1a, the annealed sample has a fully recrystallized austenitic structure with an average grain size of $\sim 100 \mu \mathrm{m}$. 

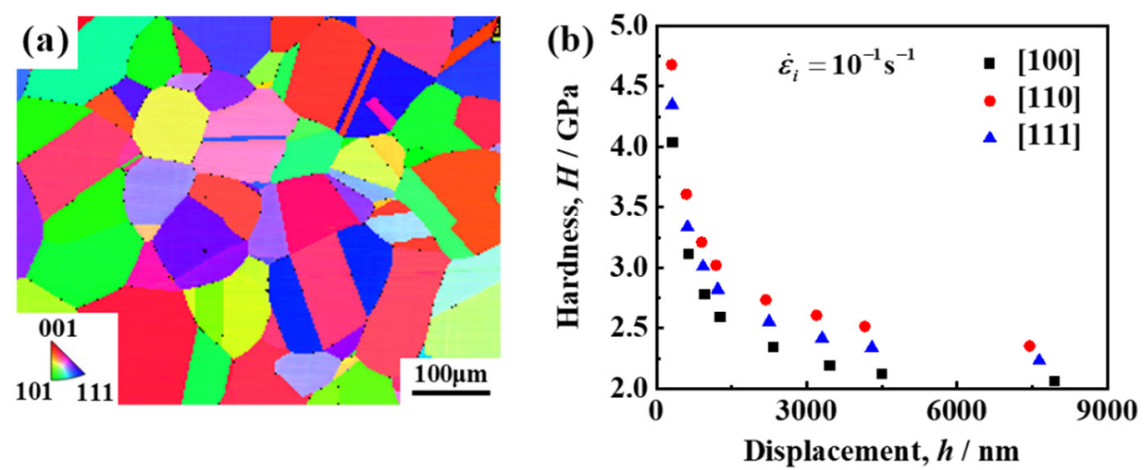

Figure 1. (a) The EBSD inverse pole figure of the fully recrystallized coarse-grained microstructure; (b) the hardness-displacement relation obtained from the CSR tests in the [001]-, [101]- and [111]oriented grains at $\dot{\varepsilon}_{i}=10^{-1} \mathrm{~s}^{-1}$

Instrumented indentation tests were carried out in a Bruker TI980 nanoindentation system with a Berkovich diamond indenter. Lucas et al. [24] proposed that the indentation strain rate $\left(\dot{\varepsilon}_{i}\right)$ for tests conducted with a geometrically self-similar indenter can be defined as:

$$
\dot{\varepsilon}_{i}=\frac{\dot{h}}{h} \approx \frac{1}{2} \frac{\dot{P}}{P},
$$

where $h$ is the displacement and $\dot{h}$ is the displacement rate. $P$ is the load and $\dot{P}$ is the load rate. For the constant strain rate (CSR) method, the instrument can control a constant $\dot{P} / P$ to obtain a constant indentation strain rate. The indentation size effect was determined in [001]-, [101]- and [111]-oriented grains by CSR indentation tests at $\dot{\varepsilon}_{i}=10^{-1} \mathrm{~s}^{-1}$ (i.e., $\left.\dot{P} / P=2 \times 10^{-1} \mathrm{~s}^{-1}\right)$ with partial unloading at various loads $(P=10,30,60,100,300$, $600,1000,3000 \mathrm{mN})$. The hardness-displacement relation is displayed in Figure $1 \mathrm{~b}$. The hardness becomes relatively constant at $h \geq 4500 \mathrm{~nm}$, corresponding to $P \geq 1000 \mathrm{mN}$. Accordingly, a peak load of $1000 \mathrm{mN}$ was used for instrumented indentation tests to obtain hardness free of the indentation size effect. The CSR tests at $\dot{\varepsilon}_{i}=10^{-1}, 10^{-2}, 10^{-3}$ and $5 \times 10^{-4} \mathrm{~s}^{-1}$ were carried out in [001]-, [101]- and [111]-oriented grains. In order to mitigate the thermal drift effects, the tests targeted at $\dot{\varepsilon}_{i}=10^{-2}, 10^{-3}$ and $5 \times 10^{-4}$ were first conducted at $\dot{\varepsilon}_{i}=10^{-1} \mathrm{~s}^{-1}$ until $P=100 \mathrm{mN}$ and then changed to the target values for the rest of the tests. The instrumented indentation tests were repeated three times for each orientation and strain rate. The data acquisition rate is $200 \mathrm{~Hz}$. Hardness $(H)$ was calculated using the Oliver-Pharr method [25].

\section{Results}

The CSR indentation tests were carried out in the [001]-, [101]- and [111]-oriented grains with the indentation strain rates targeted at $\dot{\varepsilon}_{i}=10^{-1}, 10^{-2}, 10^{-3}$, and $5 \times 10^{-4} \mathrm{~s}^{-1}$. There are three separate tests for each testing condition and Figure 2 displays the loaddisplacement curve of the test with the most serrations. The curves in each subplot were offset by a displacement offset of $500 \mathrm{~nm}$ for better demonstration. Clearly, the loaddisplacement curves show distinctive serration behaviors at different indentation strain rates and the trend is similar between different orientations. At $\dot{\varepsilon}_{i}=10^{-1} \mathrm{~s}^{-1}$, the loaddisplacement curves are smooth without any serrations, i.e., there is no PLC effect. At $\dot{\varepsilon}_{i}=10^{-2} \mathrm{~s}^{-1}$, continuous serrations appear on the load-displacement curves as successive processes of the sharp increase in load with limited displacement and the pop-in at a constant load. As $\dot{\varepsilon}_{i}$ decreases to $10^{-3} \mathrm{~s}^{-1}$, serrations become discontinuous and stochastic, with the random formation on the load-displacement curves. There are fewer serrations at $\dot{\varepsilon}_{i}=10^{-3} \mathrm{~s}^{-1}$ compared to that at $\dot{\varepsilon}_{i}=10^{-2} \mathrm{~s}^{-1}$. The number of serrations further decreases at $\dot{\varepsilon}_{i}=5 \times 10^{-4} \mathrm{~s}^{-1}$. Particularly, there is almost no serration formed at the [101] orientation. 
(a)

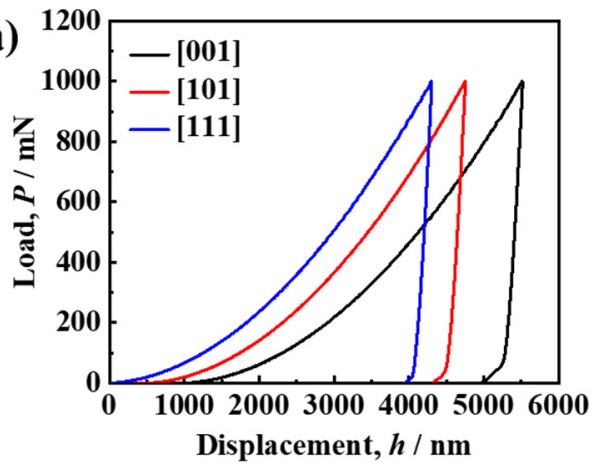

(c)

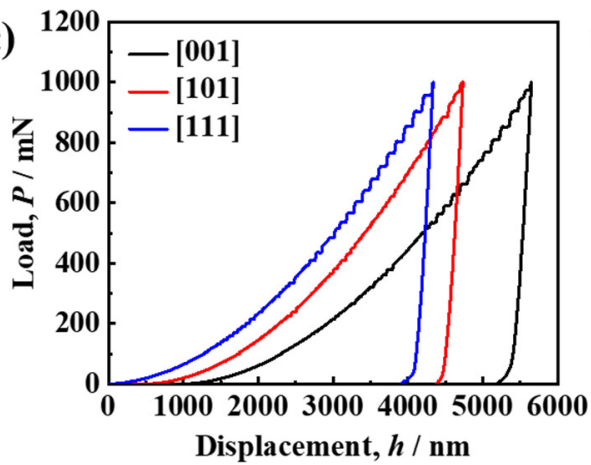

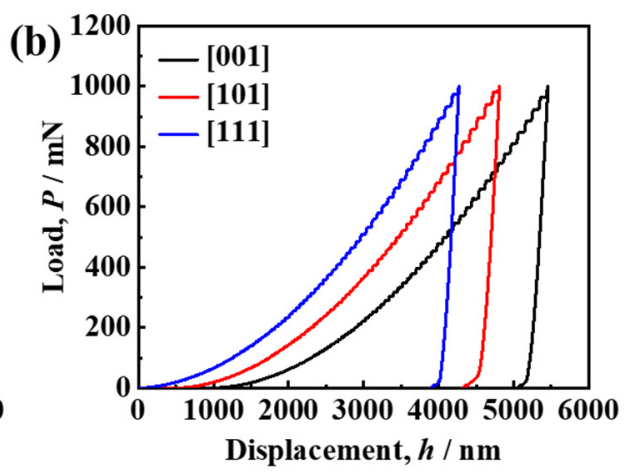

(d)

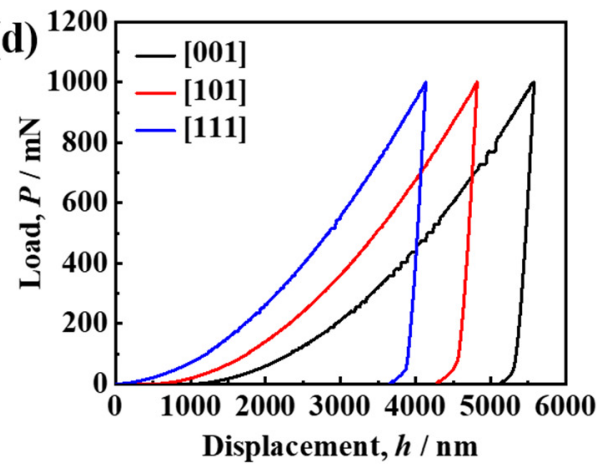

Figure 2. The load-displacement curves from the CSR tests in the [001]-, [101]- and [111]-oriented grains at (a) $\dot{\varepsilon}_{i}=10^{-1}$, (b) $10^{-2}$, (c) $10^{-3}$, and (d) $5 \times 10^{-4} \mathrm{~s}^{-1}$. The load-displacement curves at each rate were displayed with an offset of $500 \mathrm{~nm}$ between different orientations.

In addition to the rate dependence, the serration behaviors also exhibit a strong orientation dependence at the lower indentation strain rates. At $\dot{\varepsilon}_{i}=10^{-2} \mathrm{~s}^{-1}$, the serration behaviors are similar between different orientations, with continuous serrations formed on the load-displacement curves (Figure 2b). Besides, it is noted that the three separate tests in each testing condition also exhibit very similar serration behaviors. The complete experimental data can be found in Supplementary Figure S1. In contrast, the serration behaviors at $\dot{\varepsilon}_{i}=10^{-3} \mathrm{~s}^{-1}$ depend strongly on the orientation (Figure 2c). The number of serrations decreases with the orientation changed in the order of [111], [001] to [101]. As $\dot{\varepsilon}_{i}$ further decreases to $5 \times 10^{-4} \mathrm{~s}^{-1}$, there are fewer serrations formed at the [001] and [111] orientations, while the curve at the [101] orientation shows almost no serration (Figure 2d).

In order to provide a quantitative analysis of the serration behaviors at different crystal orientations and indentation strain rates, the serrations were characterized by the normalized displacement fluctuation. This parameter $(\Delta h / h)$ was obtained by first determining the displacement residual $(\Delta h)$ between the experimental and smoothed displacement-time $(h-t)$ relations, which was normalized by the total displacement $(h)$. Figure 3 displays the evolutions of $\Delta h / h$ with displacement at different orientations and indentation strain rates, which are from the same tests shown in Figure 2. No serration was observed at $\dot{\varepsilon}_{i}=10^{-1} \mathrm{~s}^{-1}$ and the amplitude of the $\Delta h / h$ peaks remains within \pm 0.005 (Figure 3a). Accordingly, $\Delta h / h= \pm 0.005$ was set as the critical value to separate serrations from the system noise. At $\dot{\varepsilon}_{i}=10^{-2} \mathrm{~s}^{-1}$, continuous $\Delta h / h$ peaks are observed and surprisingly the peak amplitude stays relatively constant with displacement. This phenomenon indicates that the displacement increment for each serration increases proportionally with the total displacement and the $\Delta h / h$ can be used to evaluate the orientation and rate effects on serrations without the influence of indentation size effect. At the lower indentation strain rates of $\dot{\varepsilon}_{i}=10^{-3}$ and $5 \times 10^{-4} \mathrm{~s}^{-1}$, the $\Delta h / h$ peaks become discontinuous and stochastic, with larger variations between peaks at the same testing condition. Since the data shown in both Figures 2 and 3 were selected from the test with the most serrations for each testing condition, they do not represent the overall orientation and rate dependencies of 
serrations and, therefore, statistical analysis was carried out based on the entire dataset as summarized below.

(a)

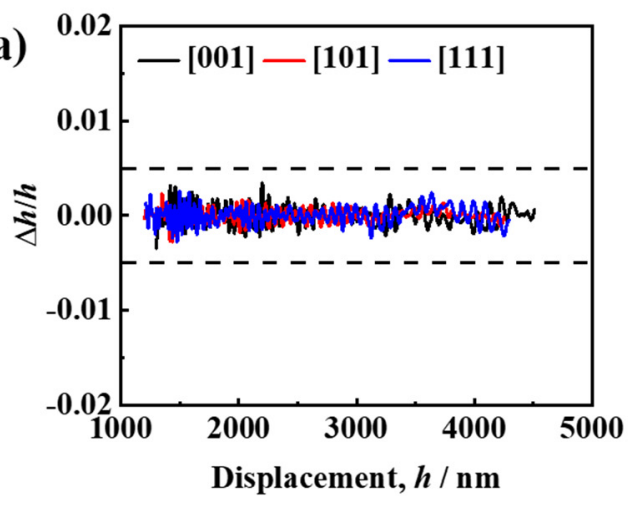

(c)

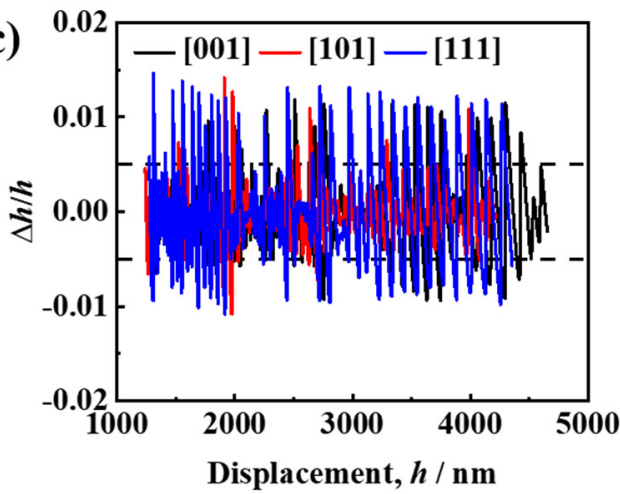

(b)

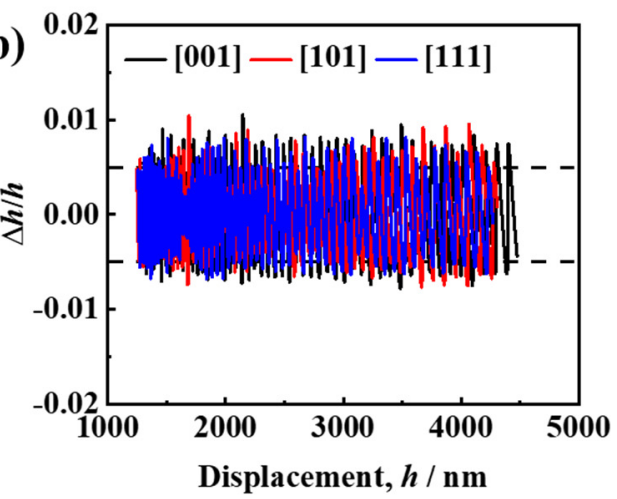

(d)

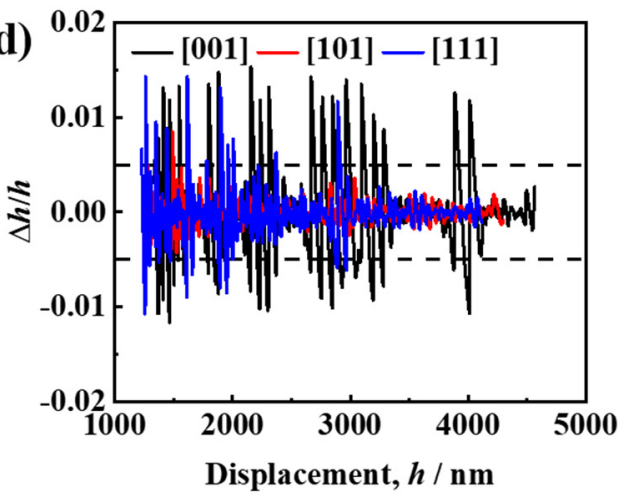

Figure 3. The evolutions of normalized displacement fluctuation $(\Delta h / h)$ with displacement during loading of the CSR tests in the [001]-, [101]- and [111]-oriented grains at (a) $\dot{\varepsilon}_{i}=10^{-1}$; (b) $10^{-2}$; (c) $10^{-3}$; and (d) $5 \times 10^{-4} \mathrm{~s}^{-1}$.

In each testing condition, the average number of serrations $\left(N_{s}\right)$ between the three independent tests and the average amplitude of all $\Delta h / h$ peaks were calculated and summarized in Figure $4 a, b$, respectively. In spite of the relatively large variations, the average number of serrations for all orientations decreases substantially with the decrease in indentation strain rate. Particularly, there is only one serration identified from the tests in the [101]-oriented grain at $\dot{\varepsilon}_{i}=5 \times 10^{-4} \mathrm{~s}^{-1}$. This phenomenon indicates that it is more difficult for serrations to occur at lower indentation strain rates. At the same indentation strain rate, the serration number generally decreases with the orientation changed in the order of [001], [111] and [101], except at $\dot{\varepsilon}_{i}=10^{-2} \mathrm{~s}^{-1}$, suggesting an increased difficulty in the occurrence of serrations. As shown in Figure $4 \mathrm{~b}$, the average amplitude of $\Delta h / h$ peaks generally increases with the decrease in indentation strain rate. The inconsistency of the results for the [111] and [101] orientations at $\dot{\varepsilon}_{i}=5 \times 10^{-4} \mathrm{~s}^{-1}$ is attributed to the limited number of serrations (Figure 4a) for evaluation. At the same indentation strain rate, the average amplitude of the $\Delta h / h$ peaks does not show a clear orientation dependence. The above statistical analysis demonstrates that for all orientations a lower indentation strain rate renders the occurrence of serrations more difficult, yet leads to serrations with generally larger displacement fluctuations once they occur. In addition, there is a strong orientation dependence in both the average number of serrations and the average amplitude of $\Delta h / h$ peaks at the lower indentation strain rates of $\dot{\varepsilon}_{i}=10^{-3}$ and $5 \times 10^{-4} \mathrm{~s}^{-1}$. 
(a)

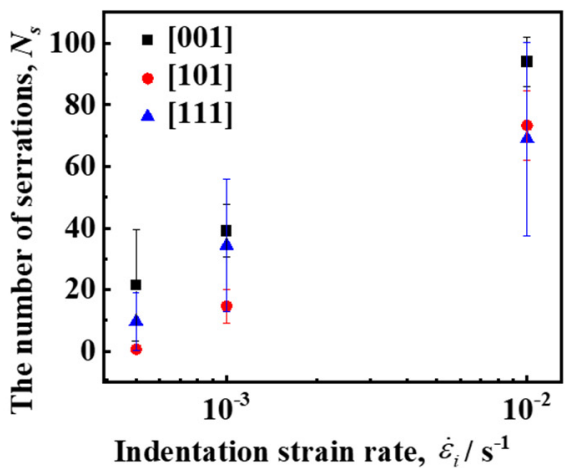

(b)

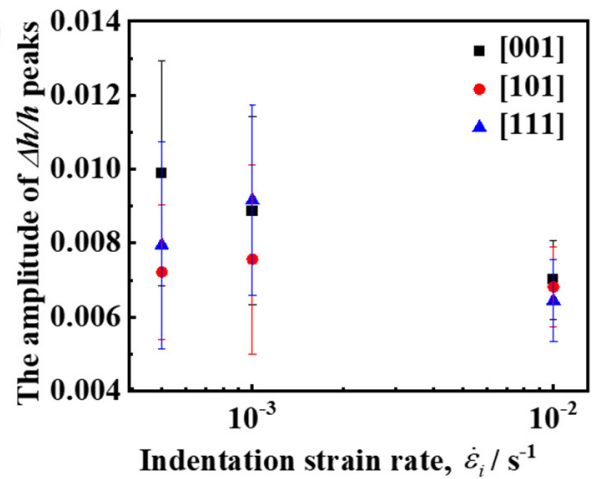

Figure 4. The evolutions of (a) the number of serrations and (b) the amplitude of $\Delta h / h$ peaks with indentation strain rate from the CSR tests in the [001]-, [101]- and [111]-oriented grains.

The rate dependence of hardness was evaluated based on the hardness obtained at the maximum load (i.e., $P=1000 \mathrm{mN}$ ) as shown in Figure 5, which is free of indentation size effect. The rate dependence of hardness is affected by the crystal orientation. The range of indentation strain rates for nSRS at the [001] orientation is: $\dot{\varepsilon}_{i}=10^{-3}-10^{-1} \mathrm{~s}^{-1}$, while that for the [101] orientation is: $\dot{\varepsilon}_{i}=10^{-2}-10^{-1} \mathrm{~s}^{-1}$. The range for nSRS at the [111] orientation appears to be: $\dot{\varepsilon}_{i}=10^{-3}-10^{-1} \mathrm{~s}^{-1}$. Nevertheless, the measured hardness at $\dot{\varepsilon}_{i}=10^{-3}$ and $5 \times 10^{-4} \mathrm{~s}^{-1}$ has relatively large variations. It is suspected that these results may be subjected to the influence of thermal drift [26]. When the thermal drift rate is less than $0.05 \mathrm{~nm} / \mathrm{s}$, the instrument starts to execute the loading program. Despite the use of early rapid loading to reduce the loading time, the loading process continued for $1000 \mathrm{~s}$ at $\dot{\varepsilon}_{i}=5 \times 10^{-4} \mathrm{~s}^{-1}$. Long time loading cannot avoid displacement data deviation. In contrast, the strain rate data of $\dot{\varepsilon}_{i}=10^{-2} \mathrm{~s}^{-1}$ will fluctuate very little.

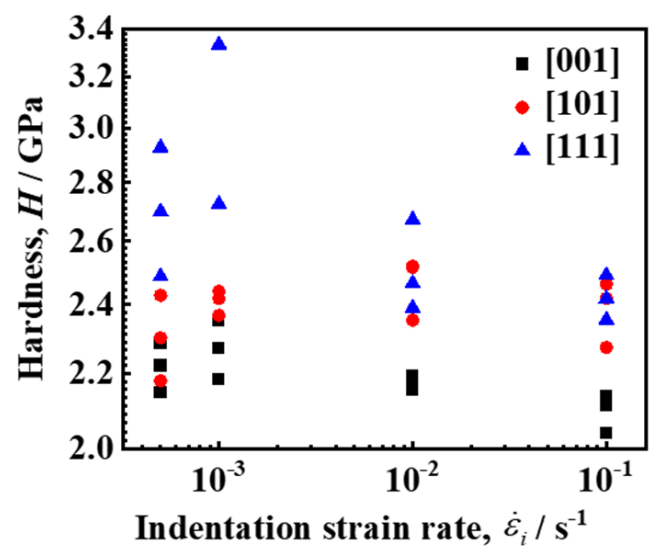

Figure 5. The relation between the hardness and indentation strain rate measured from the CSR tests in [001]-, [101]- and [111]-oriented grains.

\section{Discussion}

When certain materials are pressed in, there is a sharp increase in displacement, resulting in a serration in the load displacement curve, which is called "pop-in". Pop-ins observed in crystalline materials have been attributed to the elastic-plastic transition [27,28], martensitic transformation [29,30] and deformation twinning [31]. The serrations produced by these deformations are irregular, different from the continuous serrations observed at strain rates of $\dot{\varepsilon}_{i}=10^{-2} \mathrm{~s}^{-1}$. In addition, the serration phenomenon introduced by deformation twins and martensitic transformation generally appears in small indentation, and it has not been observed in large indentation. Here, in contrast, we found that the serration becomes larger with depth, which is caused by the increasing volume of DSA with depth. 
In uniaxial tension, the PLC effect is controlled by the ' $\mathrm{N}$ '-shaped relation between the flow stress and strain rate [32]. Provided with an applied strain rate within the range for nSRS, serrations characterized by the stress fluctuation, appear on the stress-strain curves. Similarly, the serrations in the load-displacement curves in instrumented indentation (Figure 2), are caused by nSRS, i.e., the negative rate dependence of hardness. The range of indentation strain rates for nSRS at the [001] orientation is between $10^{-3}$ and $10^{-1} \mathrm{~s}^{-1}$ (Figure 5). Accordingly, serrations for this orientation appear at $\dot{\varepsilon}_{i}=10^{-3}$ and $10^{-2} \mathrm{~s}^{-1}$ (Figure 2b,c). Interestingly, serrations also appear at $\dot{\varepsilon}_{i}=5 \times 10^{-4} \mathrm{~s}^{-1}$ (Figure 2d), which is below the lower limit for nSRS. This can be explained by the non-uniform deformation in the plastic zone beneath the indenter. Specifically, serrations may initiate in the region near the indenter, in which the actual plastic strain rate can be much higher than the applied value [33,34]. Similar phenomenon is observed at the [101] orientation, with nSRS at $\dot{\varepsilon}_{i}=10^{-2}-10^{-1} \mathrm{~s}^{-1}$ (Figure 5) and serrations formed at $\dot{\varepsilon}_{i}=10^{-3}-10^{-2} \mathrm{~s}^{-1}$ (Figure 2b,d). For the [111] orientation, nSRS appears to occur at $\dot{\varepsilon}_{i}=10^{-3}-10^{-1} \mathrm{~s}^{-1}$ (Figure 5). Nonetheless, the measured hardness at $\dot{\varepsilon}_{i}=10^{-3}$ and $5 \times 10^{-4} \mathrm{~s}^{-1}$ has relatively large variations, suggesting that they may be affected by thermal drift. Serrations at the [111] orientation occur at $\dot{\varepsilon}_{i}=5 \times 10^{-4}-10^{-2} \mathrm{~s}^{-1}$, which is slightly wider than the observed range for nSRS, despite of the potential influence of thermal drift. As discussed in Section 3, there is an increased difficulty in the occurrence of serrations at lower indentation strain rates. Yet, the serrations generally exhibit larger displacement fluctuations at lower rates [35].

According to the previous investigations, the crystal orientation that provides more active slip systems, is expected to prolong the dislocation waiting time, which facilitates the segregation of solutes at dislocation cores and, therefore, the occurrence of the PLC effect [20]. This theory has been used to explain the substantially-reduced critical stress for serrations in bulk single crystals oriented for multiple slips [20]. Besides, it has been shown that the occurrence of serrations in micro-indentation of an Al alloy depends on the azimuthal orientation angle between the diagonal of Vickers indenter and the $<110>$ direction [21]. This phenomenon has also been attributed to the orientation effects on the slip conditions. Specifically, the orientation that offers more active slip systems, facilitates the formation of serrations. Although the indentation deformation involves multiple slip systems, the number of slip systems also varies with the crystal orientation. The activated slip systems under indentation were discussed when studying the surface accumulation of grains with different crystal orientations [36,37]. The number of active slip systems decreases with the orientation changed in the order of [001], [111] and [101], although their hardness varies little [37]. As the Berkovich indenter is not strictly axisymmetric, the slip systems activated by different in-plane orientations will be different in the same normal orientation [38]. Our conclusion is based on statistical results that the orientation of the relative indenter does not affect the global orientation dependence. The main point is that the orientation dependence is dependent on the strain rate. In the current study, the number of active slip systems decreases with the orientation changed in the order of [001], [111] and [101] [36], which following the theory previously-proposed in the literature [20] should result in enhanced difficulty in the occurrence of serrations. This appears to agree with the experiments since the number of serrations at both $\dot{\varepsilon}_{i}=10^{-3}$ and $5 \times 10^{-4} \mathrm{~s}^{-1}$ decreases with the orientation changed in the order of [001], [111] and [101] (Figure 4a). Nevertheless, it is noted that such orientation effects become significant at the lower indentation rates, i.e., $\dot{\varepsilon}_{i}=10^{-3}$ and $5 \times 10^{-4} \mathrm{~s}^{-1}$ instead of $10^{-2} \mathrm{~s}^{-1}$. The formation of continuous serrations at $10^{-2} \mathrm{~s}^{-1}$ for all orientations (Figure $2 \mathrm{~b}$ ) proves that the dislocation waiting time is already long enough for the segregation of solutes to dislocations and thus the occurrence of serrations. At lower indentation strain rates of $\dot{\varepsilon}_{i}=10^{-3}$ and $5 \times 10^{-4} \mathrm{~s}^{-1}$, the dislocation waiting time is longer and more sufficient for solute segregation and the occurrence of serrations. In other words, the suppression of serrations by changing the crystal orientation at lower indentation strain rates (Figure $4 a$ ) cannot be caused by insufficient dislocation waiting time. 
Here, we proposed that the crystal orientation influences the occurrence of serrations in instrumented indentation by affecting the number of activated slip systems and, therefore, the probability of finding sufficient dislocation sources to accommodate the plastic avalanche. The experimental results demonstrate that serrations become stochastic and appear randomly on the load-displacement curves at lower indentation strain rates of $\dot{\varepsilon}_{i}=10^{-3}$ and $5 \times 10^{-4} \mathrm{~s}^{-1}$ for all orientations. Such stochastic behaviors are attributed to the reduction in the volume with sufficiently high local strain rate with the applied indentation strain rate decreased from $10^{-2}$ to $5 \times 10^{-4} \mathrm{~s}^{-1}$. This means a reduced probability of finding enough dislocations with sufficiently high velocity to initiate the plastic avalanche. At the same indentation strain rate, it is expected that the crystal orientation with more active slip systems should have a higher probability of finding sufficient dislocation sources to accommodate the plastic avalanche. Accordingly, it is easier for serrations to occur with the orientation changed in the order of [101], [111] and [001], as demonstrated by the increased number of serrations at $\dot{\varepsilon}_{i}=10^{-3}$ and $5 \times 10^{-4} \mathrm{~s}^{-1}$ (Figure 4a).

\section{Conclusions}

In this work, we applied instrumented indentation to explore the crystal orientation dependence of the PLC effect in a TWIP steel at a small scale. At a relatively high indentation strain rate (i.e., $\dot{\varepsilon}_{i}=10^{-2} \mathrm{~s}^{-1}$ ), there is no obvious difference between different orientations, which all show continuous serrations. In contrast, it is easier for serrations to occur with the orientation changed in the order of [101], [111] and [001] at lower indentation strain rates (i.e., $\dot{\varepsilon}_{i}=10^{-3}$ and $5 \times 10^{-4} \mathrm{~s}^{-1}$ ). This finding contradicts the previous proposals of the orientation effects that are associated with the dislocation waiting time. Here, we proposed that the crystal orientation influences the occurrence of serrations in instrumented indentation by affecting the number of activated slip systems and, therefore, the probability of finding sufficient dislocation sources to accommodate the plastic avalanche. At lower indentation strain rates, it is expected that the crystal orientation with more active slip systems should have a higher probability of finding sufficient dislocation sources to accommodate the plastic avalanche. This work allows us to further understand the mechanism of the PLC effect at small scales.

Supplementary Materials: The following supporting information can be downloaded at: https: / / www.mdpi.com/article/10.3390/met12030439/s1, Figure S1: The load-displacement curves from the triplicate CSR tests in the [001]-, [101]- and [111]-oriented grains at (a) $\dot{\varepsilon}_{i}=10^{-1}$, (b) $10^{-2}$, (c) $10^{-3}$, and (d) $5 \times 10^{-4} \mathrm{~s}^{-1}$. The load-displacement curves at each rate were displayed with an offset of 500 $\mathrm{nm}$ between different orientations.

Author Contributions: Conceptualization, X.P. and Z.L.; methodology, validation, investigation and writing-original draft preparation, X.P.; writing-review and editing, L.W., W.X. and Z.L.; supervision, Z.L. and W.X.; project administration, Z.L. and W.X. All authors have read and agreed to the published version of the manuscript.

Funding: This research was funded by National Natural Science Foundation of China (No. 52101146, 52011530032 and 52111530093) and Guangdong Basic and Applied Basic Research Foundation (No. 2020B1515130007).

Institutional Review Board Statement: Not applicable.

Informed Consent Statement: Not applicable.

Data Availability Statement: The data presented in this study are available on request from the corresponding author.

Conflicts of Interest: The authors declare no conflict of interest.

\section{References}

1. Le Chatelier, A. Influence du temps et de la température sur les essais au choc. Rev. Métall. 1909, 6, 914-917. [CrossRef]

2. Yilmaz, A. The Portevin-Le Chatelier effect: A review of experimental findings. Sci. Technol. Adv. Mater. 2011, 12, 063001. [CrossRef] [PubMed] 
3. Curtin, W.A.; Olmsted, D.L.; Hector, L.G. A predictive mechanism for dynamic strain ageing in Aluminium-Magnesium alloys. Nat. Mater. 2006, 5, 875-880. [CrossRef] [PubMed]

4. Van den Beukel, A. Theory of the effect of dynamic strain aging on mechanical properties. Phys. Status Solidi 1975, 30, 197-206. [CrossRef]

5. Lee, S.-J.; Kim, J.; Kane, S.N.; De Cooman, B.C. On the origin of dynamic strain aging in twinning-induced plasticity steels. Acta Mater. 2011, 59, 6809-6819. [CrossRef]

6. De Almeida, L.H.; Le May, I.; Emygdio, P.R.O. Mechanistic modeling of dynamic strain aging in austenitic stainless steels. Mater Charact. 1998, 41, 137-150. [CrossRef]

7. Van den Beukel, A.; Kocks, U.F. The strain dependence of static and dynamic strain-aging. Acta Metall. 1982, 30, 1027-1034. [CrossRef]

8. McCormick, P.G.; Ling, C.P. Numerical modelling of the Portevin-Le Chatelier effect. Acta Metall. Mater. 1995, 43, 1969-1977. [CrossRef]

9. Canadinc, D.; Efstathiou, C.; Sehitoglu, H. On the negative strain rate sensitivity of Hadfield steel. Scr. Mater. 2008, 59, 1103-1106. [CrossRef]

10. Picu, R.C.; Vincze, G.; Ozturk, F.; Gracio, J.J.; Barlat, F.; Maniatty, A.M. Strain rate sensitivity of the commercial aluminum alloy AA5182-O. Mater. Sci. Eng. A 2005, 390, 334-343. [CrossRef]

11. McCormigk, P.G. A model for the Portevin-Le Chatelier effect in substitutional alloys. Acta Metall. 1972, 20, 351-354. [CrossRef]

12. Cheng, X.M.; Morris, J.G. The anisotropy of the portevin-le chatelier effect in aluminum alloys. Scr. Mater. 2000, 43, 651-658. [CrossRef]

13. Mizera, J.; Kurzydlowski, K.J. On the anisotropy of the Portevin-Le Chatelier plastic instabilities in Al-Li-Cu-Zr alloy. Scr. Mater 2001, 45, 801-806. [CrossRef]

14. Nayan, N.; Mishra, S.; Prakash, A.; Sarkar, R.; Murty, S.; Yadava, M.; Prasad, M.; Samajdar, I. Origin of through-thickness serrated tensile flow behavior in Al-Cu-Li (AA2195) alloy: Effect of microstructure and texture. Materialia 2019, 5, 100180. [CrossRef]

15. Shabadi, R.; Kumar, S.; Roven, H.J.; Dwarakadasa, E.S. Effect of specimen condition, orientation and alloy composition on PLC band parameters. Mater. Sci. Eng. A 2004, 382, 203-208. [CrossRef]

16. Shen, Y.Z.; Oh, K.H.; Lee, D.N. The effect of texture on the Portevin-Le Chatelier effect in 2090 Al-Li alloy. Scr. Mater. 2004, 51, $285-289$. [CrossRef]

17. Hu, Z.; Qi, Y.; Nie, X.; Zhang, H.; Zhu, H. The Portevin-Le Chatelier (PLC) effect in an Al-Cu aluminum alloy fabricated by selective laser melting. Mater. Charact. 2021, 178, 111198. [CrossRef]

18. Kumar, S.; Pink, E. Serrated flow in aluminium alloys containing lithium. Acta Mater. 1997, 45, 5295-5301. [CrossRef]

19. Pink, E.; Bruckbauer, P.; Weinhandl, H. Stress-drop rates in serrated flow of aluminium alloys. Scr. Mater. 1998, 38, 945-951. [CrossRef]

20. Kalk, A.; Nortmann, A.; Schwink, C. Dynamic strain ageing and the boundaries of stable plastic deformation in Cu-Mn single crystals. Philos. Mag. A 1995, 72, 1239-1259. [CrossRef]

21. Kovács, Z.; Chinh, N.Q.; Lendvai, J. Orientation dependence of Portevin-Le Châtelier plastic instabilities in depth-sensing microindentation. J. Mater. Res. 2001, 16, 1171-1177. [CrossRef]

22. Ovri, H.; Steglich, D.; Dieringa, H.; Lilleodden, E.T. Grain-scale investigation of the anisotropy of Portevin-Le Chatelier effect in Mg AZ91 alloy. Mater. Sci. Eng. A 2019, 740, 226-234. [CrossRef]

23. Zhou, P.; Huang, M.X. On the mechanisms of different work-hardening stages in twinning-induced plasticity steels. Metall. Mater. Trans. A 2015, 46, 5080-5090. [CrossRef]

24. Lucas, B.N.; Oliver, W.C. Indentation power-law creep of high-purity indium. Metall. Mater. Trans. A 1999, 30, 601-610. [CrossRef]

25. Oliver, W.C.; Pharr, G.M. An improved technique for determining hardness and elastic modulus using load and displacement sensing indentation experiments. J. Mater. Res. 1992, 7, 1564-1583. [CrossRef]

26. Nohava, J.; Randall, N.X.; Conté, N. Novel ultra nanoindentation method with extremely low thermal drift: Principle and experimental results. J. Mater. Res. 2009, 24, 873-882. [CrossRef]

27. Bei, H.; Gao, Y.F.; Shim, S.; George, E.P.; Pharr, G.M. Strength differences arising from homogeneous versus heterogeneous dislocation nucleation. Phys. Rev. B 2008, 77, 060103. [CrossRef]

28. Shim, S.; Bei, H.; George, E.P.; Pharr, G.M. A different type of indentation size effect. Scr. Mater. 2008, 59, 1095-1098. [CrossRef]

29. Ahn, T.H.; Oh, C.S.; Kim, D.H.; Oh, K.H.; Bei, H.; George, E.P.; Han, H.N. Investigation of strain-induced martensitic transformation in metastable austenite using nanoindentation. Scr. Mater. 2010, 63, 540-543. [CrossRef]

30. He, B.B.; Huang, M.X.; Liang, Z.Y.; Ngan, A.H.W.; Luo, H.W.; Shi, J.; Cao, W.Q.; Dong, H. Nanoindentation investigation on the mechanical stability of individual austenite grains in a medium-Mn transformation-induced plasticity steel. Scr. Mater. 2013, 69, 215-218. [CrossRef]

31. Seo, E.J.; Kim, J.K.; Cho, L.; Mola, J.; Oh, C.Y.; De Cooman, B.C. Micro-plasticity of medium Mn austenitic steel: Perfect dislocation plasticity and deformation twinning. Acta Mater. 2017, 135, 112-123. [CrossRef]

32. Jiang, H.; Zhang, Q.; Chen, X.; Chen, Z.; Jiang, Z.; Wu, X.; Fan, J. Three types of Portevin-Le Chatelier effects: Experiment and modelling. Acta Mater. 2007, 55, 2219-2228. [CrossRef]

33. Takagi, H.; Fujiwara, M. Set of conversion coefficients for extracting uniaxial creep data from pseudo-steady indentation creep test results. Mater. Sci. Eng. A 2014, 602, 98-104. [CrossRef]

34. Bower, A.F.; Fleck, N.A.; Needleman, A.; Ogbonna, N.; Enderby, J.E. Indentation of a power law creeping solid. Proc. R. Soc. Lond. Ser. A Math. Phys. Sci. 1993, 441, 97-124. 
35. Chinh, N.Q.; Gubicza, J.; Kovács, Z.; Lendvai, J. Depth-sensing indentation tests in studying plastic instabilities. J. Mater. Res. 2004, 19, 31-45. [CrossRef]

36. Wang, Z.; Zhang, J.; ul Hassan, H.; Zhang, J.; Yan, Y.; Hartmaier, A.; Sun, T. Coupled effect of crystallographic orientation and indenter geometry on nanoindentation of single crystalline copper. Int. J. Mech. Sci. 2018, 148, 531-539. [CrossRef]

37. Liu, M.; Tieu, A.K.; Peng, C.-T.; Zhou, K. Explore the anisotropic indentation pile-up patterns of single-crystal coppers by crystal plasticity finite element modelling. Mater. Lett. 2015, 161, 227-230. [CrossRef]

38. Chen, S.; Miyahara, Y.; Nomoto, A. Crystallographic orientation dependence of nanoindentation hardness in austenitic phase of stainless steel. Philos. Mag. Lett. 2018, 98, 473-485. [CrossRef] 